\title{
NUMBER OF IDEAL STAGES AS AN EFFICIENCY PARAMETER FOR DISPLACEMENT WASHING OF PULP
}

\author{
FRANTIŠEK POTU゚ČEK \\ University of Pardubice, Faculty of Chemical Technology, \\ Institute of Chemistry and Technology of Macromolecular Materials, \\ 53210 Pardubice, Czech Republic \\ ¿ Corresponding author: frantisek.potucek@upce.cz
}

Received July 18, 2018

\begin{abstract}
In this paper, the concept of the number of ideal stages of dilution and thickening commonly used for the description of counter-current washing systems was applied to quantify the efficiency of displacement washing of pulp. Two kraft pulps cooked from beech and spruce, along with one soda pulp obtained from rapeseed straw and delignified to a relatively high kappa number ranging from 49.7 to 51.6, were subjected to displacement washing, using water as the wash liquid. Besides the traditional displacement ratio, the efficiency of displacement washing was expressed by the number of ideal counter-current washing stages as a function of the Péclet number and dimensionless dispersion length. The results described by the correlation equations showed that the kraft pulps cooked from beech and spruce were more easily washable, compared to soda rapeseed pulp.
\end{abstract}

Keywords: pulp, displacement washing, washing efficiency, ideal stage, displacement ratio

\section{INTRODUCTION}

In order to evaluate the efficiency of pulp washing systems, the amount of solute to be removed and the amount of water needed to accomplish this solute removal must be taken into account. With respect to further technological operations in chemical pulping of wood, pulp washing must be a compromise between the cleanliness of the pulp and the amount of water to be used. ${ }^{1}$

Two basic pulp washing techniques, namely, dilution-thickening and displacement washing, are used industrially. In dilution-thickening washing, the pulp slurry is diluted and thoroughly mixed with weak wash liquor or clean water and then thickened by filtering or by pressing. In displacement washing, weak wash liquor or clean water passes through a pulp bed in a piston-like manner, pushing out the liquor, which had been associated with the pulp. Since, for the same amount of wash water at constant discharge pulp consistency, displacement washing is more effective than washing based on dilution followed by thickening, the former has been investigated in several papers. ${ }^{2-16}$
In order to decrease the amount of wash water, several pulp washers are arranged in a countercurrent manner. The performance of a set of staged washers can be quantified by the number of equivalent ideal stages of dilution and thickening, where the incoming streams are perfectly mixed and the effluent streams are in equilibrium. ${ }^{1,17}$ In the case of pulp washing, the number of ideal stages is termed as the Norden efficiency or also the Norden efficiency factor. ${ }^{18,19}$ However, most pulp washers are based not only on the dilution-thickening principle, as the displacement plays a significant role in the washing process. Therefore, the aim of this paper was to investigate the ideal counter-current washing stage for the semi-batch displacement washing process, by characterising the efficiency of displacement washing.

\section{THEORETICAL BACKGROUND}

Let us consider a counter-current washing system, comprising $N$ ideal stages in series, as in Figure 1. The underflow is a pulp stream containing pulp and liquor with the solute to be balanced. The overflow is a wash liquor stream, 


\section{FRANTIŠEK POTU゚ČEK}

containing a solvent and a solute removed from the pulp stream. The ideal or theoretical countercurrent stage is defined as a perfect mixing stage, wherein the incoming streams are perfectly mixed and the leaving streams of the pulp and wash liquor are in equilibrium.

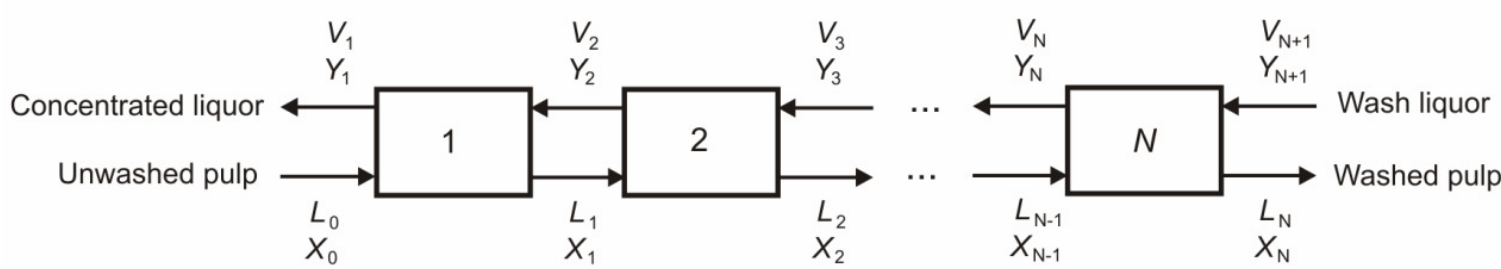

Figure 1: $N$ ideal counter-current washing stages in series

If the consistency of the pulp streams is constant and the exit streams are in equilibrium, the mass balance of the solute over the whole washing system containing $N$ stages gives the generally known the Kremser equation ${ }^{20}$ in the following form:

$D R=\frac{W^{N+1}-W}{W^{N+1}-1}$

in which the displacement ratio:

$$
D R=\frac{X_{0}-X_{N}}{X_{0}-Y_{N+1}}
$$

is defined as a decrease in the solute concentration in the pulp stream divided by the maximum decrease in pulp stream concentration, when the discharge flow of the pulp is in equilibrium with the wash liquor flow entering the $N$ th stage.

Assuming constant pulp consistency, constant liquor flow in the pulp streams, $L$, as well as constant wash liquor flow, $V$, can be desired. Moreover, when the adsorption of a solute onto fibres is ignored, the equilibrium conditions are simple because the solute concentration in the wash liquor stream is the same as that in the pulp liquor leaving the ideal stage. Hence the wash factor, $W$, is equal to the wash liquor ratio, $R W$, given as:

$$
R W=\frac{V}{L}
$$

Under these assumptions, the total number of ideal stages is defined as:

$$
N=\frac{\ln \left(\frac{R W-D R}{1-D R}\right)}{\ln R W}-1
$$

However, this situation, when pulp consistency is constant over all the washing stages, is not common. Therefore, Nordén ${ }^{21}$ derived the following relationship:

$N=\frac{\ln \left[\frac{L_{0}\left(X_{0}-Y_{1}\right)}{L_{N}\left(X_{N}-Y_{N+1}\right)}\right]}{\ln R W_{N}}$

where $N$ is usually known as the Nordén efficiency factor. ${ }^{18,19,21,22}$

The Nordén efficiency factor is defined as the number of the ideal mixing stages necessary to achieve the same departing flows, $L_{\mathrm{N}}$ and $V_{1}$, and concentrations, $X_{\mathrm{N}}$ and $Y_{1}$, as in the actual washing system or single washer. Equation (5) may also be used to calculate the number of ideal washing stages when pulp consistency varies. It is worth mentioning that both the Nordén efficiency factor, $N$, and the displacement ratio, $D R$, cannot be used generally for comparison of various washers with different inlet and discharge consistencies. Therefore, in order to compare pulp washers of different design, the equivalent displacement ratio ${ }^{1,23}$ and modified Nordén factor $^{1}$, independent of inlet and discharge consistencies, were derived. It must also be noted that Nordén and Viljakainen ${ }^{24}$ developed a method for describing counter-current washing systems, including the adsorption-desorption effects playing a significant role, mainly at low solute concentration.

Of course, for a wash liquor ratio equal to unity, Equation (5) is indeterminate. In this case, using Hospital's rule, one can obtain:

$N=\frac{L_{N}\left(Y_{1}-Y_{N+1}\right)}{L_{0}\left(X_{0}-Y_{1}\right)}$ 
in agreement with Nordén. ${ }^{21,22}$ For constant consistency of pulp flow, $L_{0}=L_{\mathrm{N}}$. In this case, when a solute is absent from the wash liquor flow entering the $N$ th stage, $Y_{\mathrm{N}+1}=0$, the numerator of Equation (6) is directly proportional to the amount of the solute in the outlet wash liquor stream, while the denominator of Equation (6) is directly proportional to the amount of the solute remaining in the leaving pulp stream, given as a difference between inlet solute mass flow in underflow and the outlet solute mass flow in the leaving overflow. This expression of the number of ideal stages by Equation (6) can also be applied to a semi-batch displacement washing process.

For a semi-batch washing system, as illustrated in previous papers, ${ }^{15,25}$ consisting of an unmovable pulp bed with black liquor, which is displaced by continuously flowing wash liquid, one can determine the number of ideal washing stages in agreement with Equation (6). If the initial pulp bed consistency remains unchanged and the wash liquor ratio is equal to unity, the number of ideal washing stages is given as:

$$
N_{\mathrm{RW}=1}=\frac{\int_{R W=0}^{R W=1} \frac{Y_{\mathrm{e}}}{Y_{0}} \mathrm{~d}(R W)}{\int_{R W=0}^{R W} \frac{Y_{\mathrm{e}}}{Y_{0}} \mathrm{~d}(R W)-\int_{R W=0}^{R W=1} \frac{Y_{\mathrm{e}}}{Y_{0}} \mathrm{~d}(R W)}
$$

where the terms on the right hand side of Equation (7) are directly proportional to the area below the displacement washing curve obtained experimentally as the dependence of the normalised exit solute concentration, $Y_{\mathrm{e}} / Y_{0}$, on the wash liquor ratio, $R W$.

The displacement ratio for $R W=1$ may be calculated from the following equation:

$$
D R_{\mathrm{RW}=1}=\frac{X_{\text {avg }, R W=0}-X_{\text {avg }, R W=1}}{X_{\text {avg }, R W=0}}
$$

where the dimensionless average solute concentration normalised as the actual average concentration inside the bed divided by the initial bed concentration at $R W=0, X_{0}$ (in Table 1), is given as:

$$
X_{\text {avg }, \mathrm{RW}=1}=\frac{\int_{R W=0}^{R W \rightarrow \infty} \frac{Y_{\mathrm{e}}}{Y_{0}} \mathrm{~d}(R W)-\int_{R W=0}^{R W=1} \frac{Y_{\mathrm{e}}}{Y_{0}} \mathrm{~d}(R W)}{\int_{R W=0}^{R W \rightarrow \infty} \frac{Y_{\mathrm{e}}}{Y_{0}} \mathrm{~d}(R W)}
$$

for $R W=1$.

It should be noted that the displacement ratio defined by Equation (8) is, at the same time, equal to the wash yield expressed as:

$$
W Y_{\mathrm{RW}=1}=\frac{\int_{R W=0}^{R W=1} \frac{Y_{\mathrm{e}}}{Y_{0}} \mathrm{~d}(R W)}{\int_{R W=0}^{R W \rightarrow \infty} \frac{Y_{\mathrm{e}}}{Y_{0}} \mathrm{~d}(R W)}
$$

which characterises the efficiency of displacement washing. Thus, Equation (7) enables us to calculate the number of ideal washing stages in series equivalent to one displacement stage at $R W$ $=1$, using clean water as wash liquid, and the displacement ratio for semi-batch arrangement of displacement washing is given by Equation (8).

\section{EXPERIMENTAL}

Two kraft pulps, from beech and spruce, and a soda rapeseed pulp were cooked in a laboratory rotary batch digester, comprising six autoclaves of $750 \mathrm{~cm}^{3}$ capacity. Beech and spruce chips were obtained from industrial mills, while rapeseed straw, in this case, of the winter hybrid genotype Artoga, was collected from the field in the Polabian lowlands (Czech Republic). The cooking conditions were described earlier. ${ }^{11,12,26}$ The degree of delignification, expressed in terms of kappa number determined as per the Tappi test method T 236 om-99 for the kraft beech, kraft spruce, and soda rapeseed pulps was equal to 51.6, 50.1 and 49.7, respectively. Using the Kajaani FS-100 instrument, the arithmetic average length, $l_{\mathrm{A}}$, and weighted average length, $l_{\mathrm{W}}$, along with fibre coarseness, $F C$, were measured for the wet state of pulp fibres. Pulp fibre properties, together with some black liquor characteristics, namely $\mathrm{pH}$ value and the initial lignin concentration, $X_{0}$, are given in Table 1. Further properties of the black liquors, which were obtained from industrial mills, can be found in previous papers. ${ }^{11,12,26}$

Displacement washing experiments simulated under laboratory conditions were performed in a cylindrical glass cell with the inside diameter of 35 $\mathrm{mm}$. Pulp beds were formed from a dilute suspension of unbeaten pulp in black liquor. After compressing to the desired thickness of $30 \mathrm{~mm}$, the consistency, i.e., mass concentration of moisture-free pulp fibres in the bed varied within the limits of 107-127, 126-136, and 82 to $125 \mathrm{~kg} \mathrm{~m}^{-3}$ for the kraft beech, kraft spruce, and soda rapeseed pulps, respectively. The pulp beds were not mechanically conditioned and were used as formed.

To investigate the displacement washing process, the stimulus-response method was chosen. Distilled water at the temperature of $25^{\circ} \mathrm{C}$, employed as a wash liquid, was distributed uniformly through the piston to the top of the bed at the start of the washing experiment, approximating a step change in the alkali lignin concentration. Samples of the washing effluent leaving the pulp bed were analysed for alkali lignin using a Cintra 10e ultraviolet spectrophotometer. 


\section{FRANTIŠEK POTU゚ČEK}

Displacement washing experiments with pulp fibres, as well as the washing equipment, were described in detail in previous papers. ${ }^{8,9,11-13}$

After completing the washing run, the volumetric flow rate of the wash liquid was measured gravimetrically at the pressure drop of $7 \mathrm{kPa}$ to determine the permeability and average porosity of the pulp bed. Analogous measurements at various consistencies of the bed were focused on the determination of the effective specific surface of pulp fibres, $a_{\mathrm{V}}$ and $a_{\mathrm{m}}$, according to Ingmanson. ${ }^{27}$

Table 1

Properties of pulp fibres and black liquors

\begin{tabular}{lcccccccc}
\hline $\begin{array}{l}\text { Raw } \\
\text { material }\end{array}$ & $\begin{array}{c}\text { Kappa } \\
\text { no. }\end{array}$ & $\begin{array}{c}a_{\mathrm{V}} \times 10^{-5} \\
\mathrm{~m}^{-1}\end{array}$ & $\begin{array}{c}a_{\mathrm{m}} \\
\mathrm{m}^{2} \mathrm{~kg}^{-1}\end{array}$ & $\begin{array}{c}l_{\mathrm{A}} \\
\mathrm{mm}\end{array}$ & $\begin{array}{c}l_{\mathrm{W}} \\
\mathrm{mm}\end{array}$ & $\begin{array}{c}F C \\
\mathrm{mg} \mathrm{m}^{-1}\end{array}$ & $\mathrm{pH}$ & $X_{0} \times 10^{2}$ \\
\hline Beech & 51.6 & 3.052 & 968 & 0.36 & 0.61 & 0.440 & 12.2 & 2.52 \\
Spruce & 50.1 & 2.073 & 701 & 2.09 & 2.84 & 0.111 & 9.2 & 5.11 \\
Rapeseed & 49.7 & 3.191 & 1277 & 0.47 & 1.11 & 0.151 & 12.0 & 2.64 \\
\hline
\end{tabular}

Note: $a_{\mathrm{V}}, a_{\mathrm{m}}-$ specific surface of fibres based on fibre volume and mass, respectively, $l_{\mathrm{A}}, l_{\mathrm{W}}-$ fibre length calculated as arithmetic and weighted average, respectively, $F C$ - fibre coarseness, $X_{0}$ - initial lignin concentration inside the pulp bed, expressed as mass fraction

\section{RESULTS AND DISCUSSION}

For displacement washing experiments, the washing and/or breakthrough curve was measured as the time dependence of the lignin concentration in the stream leaving the pulp fibre bed. In order to normalise the response record for step change in concentration, the washing curves were plotted as the dependence of the dimensionless concentration of alkali lignin in the outlet stream, expressed as the ratio of the exit concentration to the initial lignin concentration, $Y_{\mathrm{e}} / Y_{0}$, against the wash liquor ratio, $R W$, defined as the mass of wash liquid passed through the bed to the given time divided by the mass of mother liquor originally present in the bed.

The shape of the washing curve can be characterised in terms of the dimensionless Péclet number derived from the mass balance of the tracer, in our case alkali lignin, for a given system in unsteady state as follows:

$$
P e=\frac{h u}{D \varepsilon}
$$

where $h$ is the thickness of the pulp bed, $u$ is the wash liquid superficial velocity, $D$ is the longitudinal dispersion coefficient, and $\varepsilon$ is the average effective porosity of the packed bed. The evaluation of the Péclet number from the breakthrough curves was described in detail in our previous paper. ${ }^{8}$

The breakthrough curves illustrated in Figure 2 , as well as the dependence of the normalised average lignin concentration inside the pulp bed, $X_{\text {avg }}$, on the wash liquor ratio, $R W$, in Figure 3 indicate remarkable differences in the displacement washing of beech, spruce, and rapeseed pulps. It should be also noted that the displacement washing runs were finished at a wash liquor ratio above 7, when the lignin concentration in the output stream was less than one thousandth of the initial lignin concentration in the pulp bed. However, for a better optical comparison, the experimental points connected by means of the cubic spline method are illustrated only for $R W<4$.

From the dimensionless concentration profile of alkali lignin in the exit stream, it is obvious that the displacement of lignin was non-ideal. The pulp bed consisted of poly-dispersive compressible porous fibres where geometrical similarity does not exist. Moreover, the formation of a pulp bed in a washing cell influences the shape of the breakthrough curves. Even if the experimental conditions were strictly identical, the fibre bed was always different with respect to pore size distribution. Because of inhomogeneities of the fibre bed, the different local porosities influenced significantly the flow of wash liquid through the bed, mainly for short fibres of soda rapeseed pulp.

In this study, the efficiency of displacement washing was characterised by the number of ideal counter-current stages, operating under dilution and extraction principles, evaluated from Equation (7). The dependence of the number of ideal stages on the Péclet number based on bed thickness is portrayed in Figure 4 for kraft beech and spruce pulps, as well as for soda rapeseed pulp. For all the three types of pulp, the number of ideal stages increases with increasing Péclet number, but the experimental data are grouped 
according to the type of pulp, due to different morphological properties of pulp fibres. The greatest values of the number of ideal stages were achieved for kraft beech pulp where the washing curves, as well as the average lignin concentration inside the pulp bed, had the steepest record ( $c f$. Figures 2 and 3) expressed by the greatest values

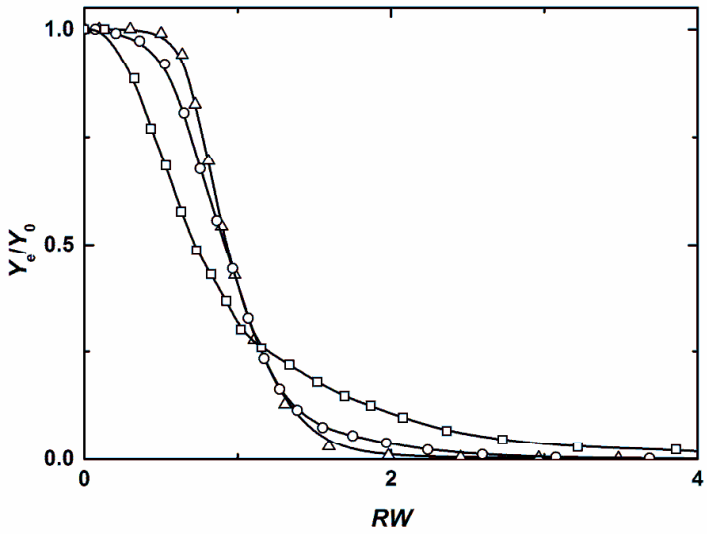

Figure 2: Typical breakthrough curves characterised by the Péclet number of 40.5, 15.1 and 4.1 for kraft beech $(\triangle)$, kraft spruce $(\bigcirc)$ and soda rapeseed $(\square)$ pulps, respectively of the Péclet number. It can be supposed that, for kraft beech pulp, the inhomogeneities in the pulp bed, such as different local porosities, influencing the displacement profile of lignin in the exit stream, were not so considerable, compared to those of kraft spruce and especially soda rapeseed pulps.

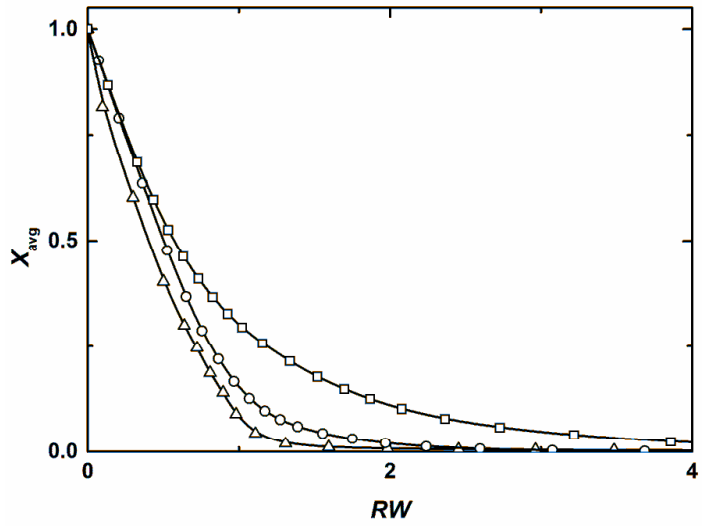

Figure 3: Normalised average alkali lignin concentration inside the pulp bed for kraft beech $(\triangle)$, kraft spruce $(\bigcirc)$, and soda rapeseed $(\square)$ pulps at the Péclet number of 40.5, 15.1 and 4.1, respectively

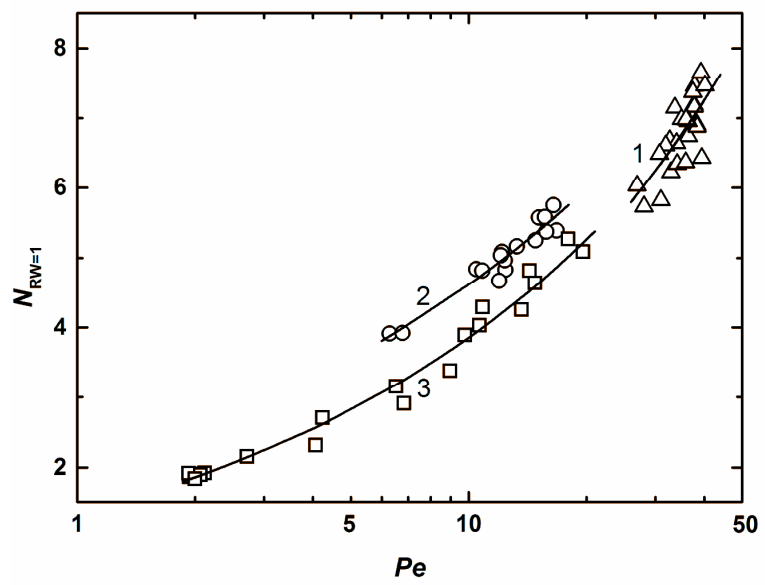

Figure 4: Number of ideal washing stages as a function of Péclet number for kraft beech $(\triangle)$, kraft spruce $(\bigcirc)$, and soda rapeseed ( $\square$ ) pulps (solid line: 1 - Eq. (12), 2 - Eq. (13), 3 - Eq. (14))

Comparing the number of ideal stages measured for kraft spruce and soda rapeseed pulps, it is obvious that the displacement washing of the kraft spruce pulp is more efficient. At the same time, one can find that a narrower interval of the Péclet number was attained for kraft spruce pulp, compared to the soda rapeseed pulp, although the conditions under which the pulp beds were formed were strictly identical. The results showed that the displacement of black liquor from the soda rapeseed pulp was accomplished with greater difficulties, in comparison with that of the kraft pulps cooked from beech and spruce wood. As follows from Figure 4, one displacement washing stage, when water is used as a wash liquid at the wash liquor ratio $R W=1$, corresponds to the number of ideal dilutionthickening stages of 5.9 to 7.6 , of 3.9 to 5.6, and of 1.8 to 5.2 for kraft beech, kraft spruce, and soda rapeseed pulps, respectively. These results 
obtained under laboratory conditions revealed unambiguously that, for the same amount of wash water, displacement washing is more efficient

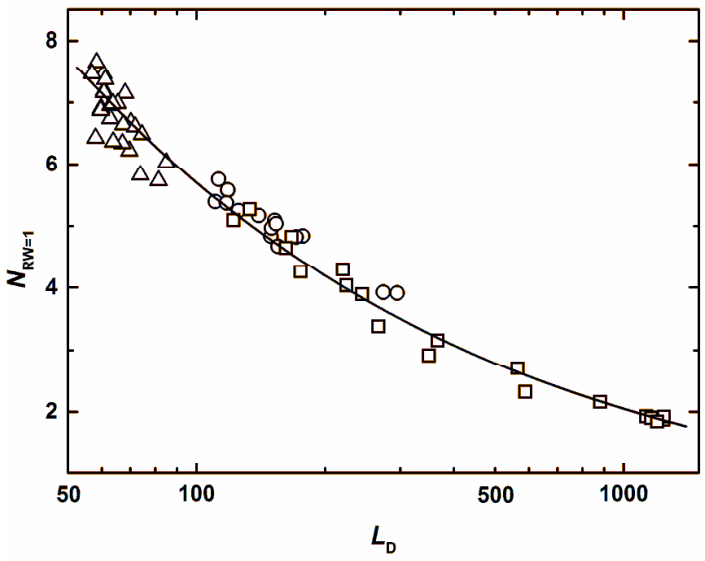

Figure 5: Number of ideal washing stages as a function of dimensionless dispersion length for kraft beech $(\triangle)$, kraft spruce $(\bigcirc)$, and soda rapeseed $(\square)$ pulps (solid line - Eq. (15))

The dependences between the number of ideal stages and the Péclet number were described by the correlation equations. For kraft beech pulp, the following correlation:

$N_{R W=1}=1.06 P e^{0.522}$

with a mean relative deviation of $5.0 \%$, $95 \%$ confidence limits of the coefficient $(0.911 ; 1.202)$ and of the power of the Péclet number $(0.475$; 0.569) was derived in the Péclet number range from 26.9 to 40.2 , and for kraft spruce pulp, the following correlation:

$N_{R W=1}=1.94 P e^{0.375}$

with a mean relative deviation of $2.7 \%, 95 \%$ confidence limits of the coefficient $(1.879 ; 2.011)$ and of the power of the Péclet number $(0.361$; 0.389) was derived in the Péclet number range from 6.3 to 16.8 . As for soda rapeseed pulp, the following correlation:

$N_{R W=1}=1.36 P e^{0.451}$

with a mean relative deviation of $5.0 \%, 95 \%$ confidence limits of the coefficient $(1.347 ; 1.381)$ and of the power of the Péclet number $(0.444$; $0.457)$ was derived in the Péclet number range from 1.9 to 19.6 .

It is worth mentioning that the Akaike information criterion as an estimator of the relative quality of statistical models has a value of $-49,-59$, and -67 for Equations (12), (13), and (14), respectively. One can suppose that the lower than washing based on dilution followed by thickening

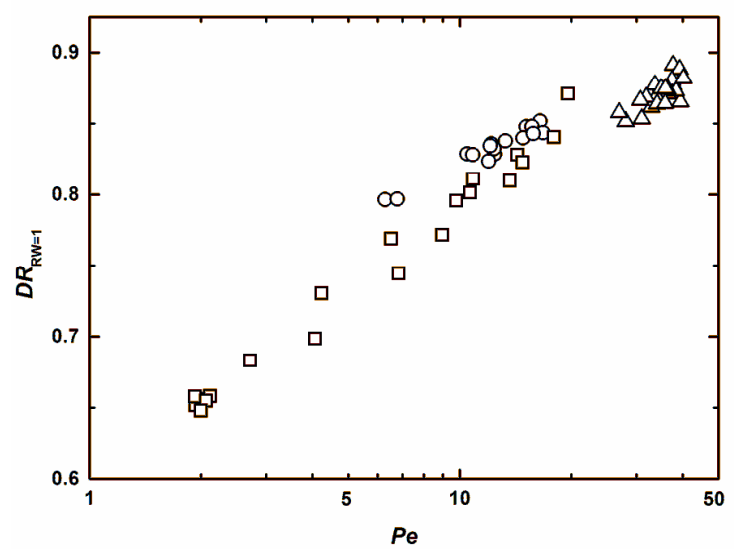

Figure 6: Displacement ratio as a function of Péclet number for kraft beech $(\triangle)$, kraft spruce $(\bigcirc)$, and soda rapeseed ( $\square$ ) pulps

Akaike information criterion, the more suitable the statistical model is.

Owing to the stochastic character of the unmovable pulp fibre bed, consisting of compressible porous fibres with different length, the influence of the dimensionless dispersion length, $L_{\mathrm{D}}=h a_{\mathrm{V}} / 4 P e,{ }^{28}$ on the number of ideal stages is shown in Figure 5. The values of the dimensionless dispersion length ranging from 58 to 1,240 confirm that pulp fibre beds where particles are randomly arranged during bed formation rank with dispersive media. ${ }^{28}$

The relation between the number of ideal stages and dimensionless dispersion length may be expressed in the following form:

$N_{R W=1}=43.9 L_{D}^{-0.443}$

with a mean relative deviation of $5.9 \%, 95 \%$ confidence limits of the coefficient $(43.4 ; 44.3)$ and of the power of the Péclet number $(-0.445$; 0.441) for all the types of pulp tested in this work. The Akaike information criterion was found to be -144 .

Figure 6 indicates the influence of the Péclet number on the displacement ratio at $R W=1$ defined by Equation (8), which corresponds to the traditional wash yield. The results show remarkable differences in displacement washing for beech, spruce and rapeseed pulps. However, comparing Figures 4 and 6 , it is obvious that the results obtained for the number of ideal stages 
agree fairly well with those for the wash yield reported in our previous papers, ${ }^{11,12}$ where it was found that the wash yield for kraft softwood pulp was lower than that for hardwood pulp, ${ }^{11}$ but it was greater than that measured for the soda rapeseed pulp. ${ }^{12}$ Thus, it seems that the soda rapeseed pulp is the least easily washable, compared to the kraft beech and spruce pulps.

\section{CONCLUSION}

Based on our data measured under laboratory conditions, some conclusions valid within the framework of this study can be drawn.

The results obtained illustrated that the number of ideal stages of dilution and thickening, commonly considered for counter-current washing systems, can be used for describing the efficiency of displacement washing. Similarly as for the wash yield, the number of ideal stages increases with increasing the Péclet number, and decreases simultaneously with increasing the dimensionless dispersion length for all the types of pulp tested in this work. It revealed that soda rapeseed pulp is more difficultly washable, in comparison with kraft spruce and kraft beech pulps. Since the displacement washing is more effective than washing based on dilution and thickening using the same amount of wash water, one displacement stage at the wash liquor ratio equal to unity was the equivalent of 5.9 to 7.6 , of 3.9 to 5.6 , and of 1.8 to 5.2 ideal washing stages for kraft beech, kraft spruce, and soda rapeseed pulps, respectively.

ACKNOWLEDGEMENTS: This work was supported by the Ministry of Education, Youth and Sports of the Czech Republic under the research project SGS_2018_006.

\section{SYMBOLS}

$a_{\mathrm{m}} \quad$ specific surface of pulp fibres based on fibre mass, $\mathrm{m}^{2} \mathrm{~kg}^{-1}$

$a_{\mathrm{V}} \quad$ specific surface of pulp fibres based on fibre volume, $\mathrm{m}^{-1}$

$D \quad$ axial dispersion coefficient, $\mathrm{m}^{2} \mathrm{~s}^{-1}$

$D R \quad$ displacement ratio defined by Eq. (2)

$F C$ fibre coarseness, $\mathrm{mg} \mathrm{m}^{-1}$

$h$ bed thickness, $\mathrm{m}$

$L \quad$ mass flow of liquor in pulp stream, $\mathrm{kg} \mathrm{s}^{-1}$

$l \quad$ fibre length, $\mathrm{mm}$

$L_{\mathrm{D}} \quad$ dispersion length, dimensionless

$N$ number of ideal stages in series (Nordén efficiency factor for pulp washing)

$P e \quad$ Péclet number based on the thickness of the bed and defined by Eq. (11), dimensionless

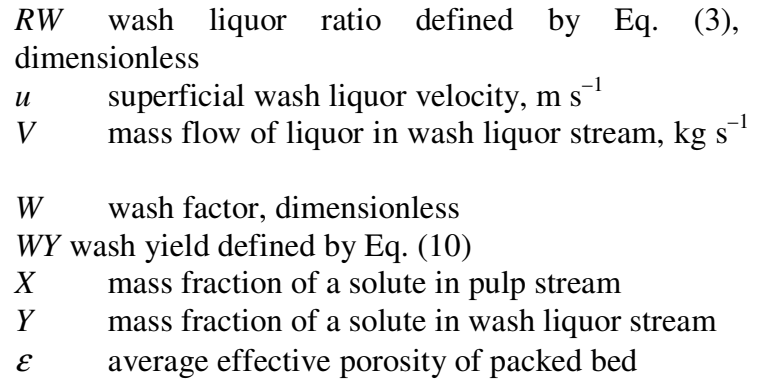

\section{Subscripts}

A referring to arithmetic average

avg referring to average

e referring to exit stream

$\mathrm{RW}=0 \quad$ referring to start of washing

$\mathrm{RW}=1$ referring to wash liquor ratio equal to

unity

W referring to weighted average

$0,1, i, N \quad$ referring to theoretical stage

\section{REFERENCES}

1 R. H. Crotogino, N. A. Poirier and D. T. Trinh, Tappi J., 70, 95 (1987).

2 L.-E. Grähs, Svensk Papperstidn., 79, 123 (1976).

3 P. F. Lee, Tappi J., 62, 75 (1979).

4 N. A. Poirier, R. H. Crotogino, D. T. Trinh and W. J. M. Douglas, in Procs. Pulp Washing Symposium, Finnish Pulp and Paper Research Institute, Finland, May 18-21, 1987, pp. 1-19.

5 D. T. Trinh, N. A. Poirier and R. H. Crotogino, in Procs. Pulp Washing Symposium, Finnish Pulp and Paper Research Institute, Finland, May 18-21, 1987, pp. 21-34.

N. A. Poirier, R. H. Crotogino and W. J. M. Douglas, Can. J. Chem. Eng., 66, 936 (1988).

7 D. T. Trinh, N. A. Poirier, R. H. Crotogino and W. J. M. Douglas, J. Pulp Paper Sci., 15, J28 (1989).

8 F. Potůček, Collect. Czech. Chem. Commun., 62, 626 (1997).

9 F. Potůček and M. Marhanová, Chem. Pap., 54, 221 (2000),

https://www.chempap.org/file_access.php?file=566a36 9.pdf

10 F. Potůček, Pap. Celul., 56, 8 (2001).

11 F. Potůček and J. Miklík, Acta Facult. Xylol. Zvolen, 53, 45 (2011).

12 F. Potůček and K. Hájková, Acta Facult. Xylol. Zvolen, 58, 35 (2016).

13 F. Potůček and M. Marhanová, Cellulose Chem. Technol., 36, 527 (2002).

14 F. Potůček, Cellulose Chem. Technol., 37, 391 (2003).

15 S. Arora and F. Potůček, Cellulose Chem. Technol., 43 , 307

(2009), 


\section{FRANTIŠEK POTU゚ČEK}

http://www.cellulosechemtechnol.ro/pdf/CCT7-82009/p.307-315.pdf

16 F. Potůček and I. Skotnicová, Cellulose Chem. Technol., $\quad 47, \quad 777$ http://www.cellulosechemtechnol.ro/pdf/CCT910(2013)/p.777-782.pdf

17 P. W. Oxby, T. D. Sandry and D. M. Kirkcaldy, Tappi J., 69, 118 (1986).

18 H. H. Nierman, Tappi J., 69, 85 (1986).

19 H. H. Nierman, Tappi J., 69, 122 (1986).

20 W. L. McCabe, J. C. Smith and P. Harriott, "Unit Operation of Chemical Engineering", sixth ed., McGraw-Hill, Boston, 2001.

21 H. V. Nordén, Kemian Teollisuus, 23, 343 (1966).

22 H. V. Nordén and M. Järveläinen, Kemian Teollisuus, 23, 586 (1966).

23 O. Luthi, Tappi J., 66, 82 (1983).
24 H. V. Nordén and E. Viljakainen, Svensk Papperstidn., 83, 50 (1980).

25 F. Potůček and M. M. Rahman, Cellulose Chem. Technol., $\quad 36, \quad 393$ http://www.cellulosechemtechnol.ro/pdf/CCT56(2018)/p.393-401.pdf

26 F. Potůček and M. M. Rahman, in Procs. $6^{\text {th }}$ Int. Conf. Chem. Technol., Mikulov, 2018.

27 W. L. Ingmanson, Chem. Eng. Prog., 49, 577 (1953).

28 E. Mauret and M. Renaud, Appita J., 55, 123 (2002). 